\title{
De Economische Faculteit in Maastricht : een intentie in praktijk gebracht
}

Citation for published version (APA):

van Loon, P. J. J. M. (1986). De Economische Faculteit in Maastricht : een intentie in praktijk gebracht. Maastricht University. https://doi.org/10.26481/spe.19860110pl

Document status and date:

Published: 10/01/1986

DOI:

10.26481/spe.19860110pl

Document Version:

Publisher's PDF, also known as Version of record

\section{Please check the document version of this publication:}

- A submitted manuscript is the version of the article upon submission and before peer-review. There can be important differences between the submitted version and the official published version of record.

People interested in the research are advised to contact the author for the final version of the publication, or visit the DOI to the publisher's website.

- The final author version and the galley proof are versions of the publication after peer review.

- The final published version features the final layout of the paper including the volume, issue and page numbers.

Link to publication

\footnotetext{
General rights rights.

- You may freely distribute the URL identifying the publication in the public portal. please follow below link for the End User Agreement:

www.umlib.nl/taverne-license

Take down policy

If you believe that this document breaches copyright please contact us at:

repository@maastrichtuniversity.nl

providing details and we will investigate your claim.
}

Copyright and moral rights for the publications made accessible in the public portal are retained by the authors and/or other copyright owners and it is a condition of accessing publications that users recognise and abide by the legal requirements associated with these

- Users may download and print one copy of any publication from the public portal for the purpose of private study or research.

- You may not further distribute the material or use it for any profit-making activity or commercial gain

If the publication is distributed under the terms of Article $25 \mathrm{fa}$ of the Dutch Copyright Act, indicated by the "Taverne" license above, 


\section{De Economische Faculteit in Maastricht: een intentie in praktijk gebracht.}

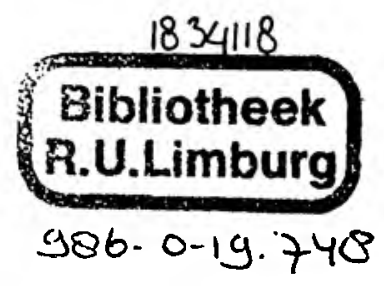

Diesrede gehouden door

Prof. dr. P.J.J.M. van Loon

ter gelegenheid van het $2 \mathrm{e}$ lustrum

van de Rijksuniversiteit Limburg

10 januari 1986 


\section{DE ZUSTERFACULTEITEN}

Dames en Heren,

Een aap leidt een ander economisch leven dan de homo sapiens. Een veel primitiever leven zelfs, in onze ogen, waar nauwelijks sprake is van goederenruil laat staan geldverkeer. Toch circuleren onder economen een aantal klassieke cases uit de apenwereld als, vermeende, karikaturen van menselijk gedrag in beslissingssituaties met een economische context.

Zo is er het verhaal van de apenrots. In een dierenpark kregen een aantal vrouwtjesapen een afgeschermd gebied voor zich alleen toegewezen. Er groeide een sociaal gedragspatroon tussen de beesten, uiteraard met een zekere hiërarchie welke voor wetenschappelijke waarnemers af te lezen was uit de plaats van iedere apin op de rots. Zodra dit patroon een stabiel karakter vertoonde, werd een nieuwkomer, een mannelijke aap, op het terrein losgelaten, met als doel te bezien hoe deze in de leefgemeenschap zou worden opgenomen. De nieuwkomer, met zijn andere fysieke kenmerken, zou in menig opzicht een verrijking van het commune-leven kunnen betekenen. Geen der apinnen maakte aanstalten om dit te gaan verkennen. Integendeel, ieder was erop uit haar positie op de apenrots met hand en tand te verdedigen en maakte met alle fysiek beschikbare middelen duidelijk dat het heerschap niet welkom was.

Een beschaafdere vorm van het apenrots verhaal komen we tegen bij de homo sapiens (van de species: mercator) in een situatie, waarbij op een min of meer afgeschermde markt concurrenten elkaar gevonden hebben en een nieuwkomer met een gelijksoortig produkt probeert zich een plaats op deze markt te veroveren. En om zo'n situatie te beschrijven wordt dan wel eens door economen het apenrots verhaal aangehaald.

In een nog beschaafdere vorm kwam ik het tegen bij de voorbereiding van deze rede, waartoe ik wat rondgesnuffeld heb in de levendige correspondentie over de oprichting van onze faculteit tussen de sectie Economie van de Academische Raad, waarin vertegenwoordigers zitten van de Nederlandse Economische Faculteiten, de Minister van Onderwijs \& Wetenschappen en onze instelling. De eerste reactie van de zusters in de Academische Raad had iets van dat afhoudende van de rotsbewoonsters. Een natuurlijke reactie, zo lijkt het, want op dezelfde wijze bijvoorbeeld reageerde in het begin van deze eeuw de Katholieke Universiteit Nijmegen op de voornemens om in Tilburg een Economische Faculteit in te 
richten (1). Maar in een mengeling van dompteurs- en diplomaten tactiek lukte het de Limburgse verloskundigen de jongste dochter reeds voor de bevalling getolereerd te krijgen door de zusters. En ik kan u vertellen dat de zusters nu ook nieuwsgierig beginnen te worden: regelmatig komen er belangstellenden langs om zelf te ervaren wat economisch onderwijs volgens het Maastrichtse systeem betekent en we horen dat elders pogingen worden ondernomen om elementen uit ons programma over te nemen. Ook vertrouwde de toenmalige voorzitter van de sectie Economie me onlangs toe dat hij met plezier, en enigszins met afgunst, de coöperatie tussen vakgebieden binnen onze faculteit gestalte zag krijgen. waar dat elders niet of nauwelijks lukt. Kortom, de zusters begonnen enige tederheid te vertonen voor het borelingske.

Deze acceptatie is een levensvoorwaarde voor onze nog kleine faculteit. Daarom ben ik verheugd over het feit, dat ons uit bestuurlijke kringen in het kader van de discussie over de uitgroei van deze instelling tot een volwaardige universiteit, steeds meer signalen bereiken dat een omvang van onze faculteit, waarbij jaarlijks zo'n 500 nieuwe studenten instromen wel erg ambitieus is. Dat zou immers betekenen dat onze faculteit zou uitgroeien tot de grootste economische faculteit van Nederland na Rotterdam (rekening houdend met de gevolgen van zo'n faculteit in Maastricht voor de instroom bij onze zusterfaculteit in Tilburg). Zo'n koekoeksjong zullen de zusters toch niet accepteren? Afgezien van de vraag of voor zo'n groot beest voldoende voedsel in de omgeving te vinden is.

Daarom ben ik blij met de signalen dat er een groeiende druk op de heren politici is om de, hier beroemde, motie Deetman, waarin de uitgroei van deze instelling naar 6000 studenten wordt gewaarborgd, op meer realistische wijze ten uitvoer te brengen. Dat wil zeggen: door naast een economische en juridische faculteit van normale omvang het licht op groen te zetten voor de vestiging van andere faculteiten. Daarbij zou ik ervoor willen pleiten deze te zoeken in de nog niet vertegenwoordigde wetenschappelijke clusters met name in de alpha en bèta hoek.

Met deze uitspraak wil ik niet tornen aan het belang te zoeken naar nieuwe afstudeervarianten en studierichtingen binnen en tussen de reeds aanwezige faculteiten. Integendeel, dat proces is alleen al noodzakelijk om mee te kunnen blijven draaien in een markt waarin het onderwijsaanbod permanent aan vernieuwing onderhevig is. Immers, ook collegainstellingen van wetenschappelijk en hoger beroepsonderwijs zijn op dezelfde wijze haar onderwijsaanbod aan het veranderen.

De kracht van onze instelling ligt in dit kader in haar gerichtheid op interdisciplinair onderwijs en onderzoek. Dat trekt vakmensen aan die 
bereid zijn om in steeds wisselende combinaties met andere disciplines samen te werken. Daardoor wordt de flexibiliteit van de inzet van wetenschappelijke arbeid belangrijk gestimuleerd en kan adequaat ingespeeld worden op een veranderende vraag naar onderwijs en onderzoek.

\section{DE CONTOURENNOTA}

Maar, dames en heren, ik loop vooruit op het slot van mijn betoog over de intentie voor de toekomst. Laat ik eerst met $u$ teruggaan naar het ontstaan van de intentie. Ik zal niet ingaan op de vraag hoe, waar en wanneer de idee ontstaan is om over een economische faculteit in Maastricht na te gaan denken. Ik beschouw die periode in deze lezing als de oertijd waarin het gistte en borrelde, waarin de eerste ideeën zich aaneenregen, maar waarvan we ons vandaag met een amorf beeld tevreden moeten stellen. Zoiets als de beginmaten van "La Valse" van Ravel, waarin donkere basen hoorntonen de oermassa weergeven. Daaruit maken zich dan langzamerhand de thema's los, de embryo's die later uit zullen groeien tot complete walsen. De eerste thema's die zich voor ons op schrift waarneembaar opheffen uit de oermassa, vinden we in een nota geschreven door het Bureau Onderzoek van Onderwijs van de Rijksuniversiteit Leiden. In een verbazend korte tijd van amper vier maanden, zijnde de periode tussen de opdracht door de Algemene Faculteit en het aanbieden van de nota aan Pais, waren de eerste thema's ontworpen. Die snelheid was nodig om Pais de gelegenheid te geven vóór zijn vertrek als minister op basis van een gemotiveerd en inhoudelijk aangekleed verzoek van onze instelling, "ja" te kunnen zeggen. Dat deed hij op 9 september van datzelfde jaar.

Zoals gezegd, behandelt het betreffende rapport, "De contouren van een economische faculteit aan de R.U. Limburg" geheten, enkele thema's waarvan er een aantal ook nu nog doorklinkt in het functioneren van onze faculteit.

Zo wordt in deze nota gepleit voor een praktijkgerichte opleiding. Dat wil zeggen dat de problemen welke de student voorgelegd krijgt zoveel mogelijk uit de beroepspraktijk van economen gehaald moeten worden. Bekijken we wat daarvan in het studieprogramma terecht is gekomen, dan zien we dat het in de eerste twee jaren van de opleiding reeds gelukt is een meerderheid van die problemen daarop te enten dankzij de medewerking van een twintigtal organisaties van verschillende pluimage: grootindustrie, kleinbedrijf, overheid, dienstverlening, regionale en (inter)nationale bedrijven, noemt $u$ maar op. Daarbij is het gelukt enerzijds 
alle relevante onderwerpen voor een basis economie opleiding aan de orde te stellen, anderzijds de studenten een representatief beeld te geven van de dagelijkse praktijk van economen werkzaam in het bedrijfsleven en in de non-profit sector.

\section{NUMERUS FIXUS}

Laten we terugkeren naar het oprichtingsproces waarin de zojuist besproken nota voor Pais het instrument was om een intentieverklaring tot de oprichting van een economische faculteit af te geven. Dat was begin september 1981. Inmiddels komen de zusterfaculteiten in de sectie Economie van de Academische Raad in het geweer, haar argumentatie enerzijds stoelend op de toen verwachte landelijke terugval in belangstelling voor economische studierichtingen, anderzijds op al dan niet vermeende bezwaren tegen de opzet en de inhoud van het studieprogramma. Pais' opvolger Deetman maakte op 16 juni 1982, ruim negen maanden na het ja-woord, aan het gekibbel een einde in een wat kribbige brief aan de Academische Raad. Daarin onderstreepte hij het politieke karakter van de keuze van genoemde vestiging. Verder geeft hij aan dat de faculteit in 1984 of 1985 kan starten met circa 100 eerstejaars en dient uit te groeien tot een capaciteit in 1986 resp. 1987 van ca. 300 eerstejaars.

Dat betekent dus een faculteit van ongeveer gelijke grootte als de zusterfaculteiten aan de Gemeentelijk en de Vrije Universiteit te Amsterdam en aan de Rijksuniversiteit te Groningen. Dat vindt onze faculteit een realistisch streven. Niet dat we die studentenstroom in 1986 al kunnen behappen. Maar dat komt niet door gebrek aan belangstelling bij de studenten. Integendeel evenals de afgelopen twee jaren verwachten we, gegeven de belangstelling op de in het najaar gehouden abituriëntendag, ook het komende academisch jaar meer aanmeldingen dan de capaciteit die we aan kunnen bieden. We zullen onze numerus fixus dus ook dit jaar weer moeten handhaven. De oorzaak daarvan ligt enerzijds in de tijdrovende inrichting van het onderwijsprogramma, anderzijds in de trage instroom van wetenschappelijk personeel, met name in de bedrijfseconomische vakken. En dat zijn net de vakken waar het merendeel der studenten voor kiest. Deze trage instroom wordt veroorzaakt door de lage salarissen die wij nieuwe medewerkers kunnen bieden in vergelijking tot de bedragen die zij in het bedrijfsleven kunnen verdienen. Ook schrikt het carrièreperspectief en soms ook het werkklimaat bij een aantal zusterinstellingen pas afgestudeerden af om voor een academische carrière te kiezen. Het persen van een bestaande organisatiestructuur in de nieuwe BUWP-structuur met haar goedkope salarisopbouw en afnemende carrièremogelijkheden, de inkrimpingsmaatregelen welke genomen moeten worden in 
het kader van de TVC-procedure, de hoge onderwijslast met name bij de meeste bedrijfseconomische vakgroepen vanwege de toenemende belangstelling voor bedrijfsgerichte afstudeerrichtingen en varianten, het zijn alle factoren die een aantal veelbelovende talenten doet afzien van een wetenschappelijke carrière aan een Nederlandse economische faculteit. Dit heeft ook zijn weerslag op de belangstelling voor een carrière aan onze faculteit, hoewel wij niet met reorganisatie-problemen te maken hebben.

Zolang deze situatie niet verandert, bijvoorbeeld doordat de minister ons grotere vrijheid biedt in het vaststellen van de salariëring, valt de eerstkomende jaren niet te ontkomen aan een numerus fixus, gezien de belangstelling van studenten voor onze faculteit. Een belangstelling die zeker nog zal toenemen zodra de profilering van onze afstudeervarianten, de kwaliteit van ons onderwijsprogramma en onderwijssysteem en, niet te vergeten, de omvang en kwaliteit van ons onderzoek conform de planning gerealiseerd gaan worden en landelijke bekendheid zullen krijgen.

Dames en heren, na deze uitwijding over studentenaantallen, een uitwijding die ik noodzakelijk achtte om een aantal gerezen misverstanden over lege schoolbanken bij onze faculteit te ontzenuwen en op het tegendeel te wijzen: dat we voorlopig de vraag niet aan kunnen, keer ik met $u$ terug naar de historische ontwikkeling van onze facultaire intentie. We waren bij de brief van Deetman van juni 1982, waarin hij een Economische faculteit met, uiteindelijk, een capaciteit van 300 eerstejaars toezegde.

\section{NOTA "ECONOMIE IN MAASTRICHT"}

Het volgende wapenfeit was de benoeming van Albeda tot bouwdecaan van onze faculteit per 1 augustus van hetzelfde jaar. Samen met de 4 dagen eerder ingestelde Werkgroep Economie, bestaande uit interne deskundigen, produceerde hij het tweede belangrijke document in de wordingsgeschiedenis van onze faculteit, de "Globale visie over een economie-opleiding in Maastricht", welke begin 1983 in de verschillende universitaire gremia en in de Academische Raad werd besproken. Op de inhoud van dit stuk ga ik hier niet verder in, temeer daar vlak daarna de nota "Economie in Maastricht"(3) verscheen, welke op 17 februari 1983 aan het bestuur van de Algemene Faculteit werd aangeboden. Dit document vormde uiteindelijk het kompas waarop de kwartiermakers van de Faculteit zouden gaan varen. Het was een bijstelling van eerdergenoemde "Globale visie" op basis van gesprekken met de AR en met een groep extern aangeworven consulenten. 
Duidelijk wordt er meer aandacht besteed aan de Bedrijfseconomische inbreng. Van een bescheiden subthema in de eerste nota, promoveert het tot een geloofwaardig tweede hoofdthema naast Algemene Economie in deze nota, zo lezen we in een passage op pag. 11: "Aangezien de meerderheid van de economen zich op de arbeidsmarkt op de een of andere wijze zal richten op de bedrijfseconomie, zal de bedrijfseconomie tenminste een even zwaar accent in de opleiding dienen te krijgen als de algemene economie".

Een ander thema dat in deze nota verder uitgewerkt wordt is de doelstelling van het onderwijs. Of beter: er vindt een omkering van het thema plaats: In plaats van "wat doet een econoom?" uit de eerste nota lezen we nu "wat behoort een econoom te weten?". Het antwoord op de ene vraag hangt samen met het antwoord op de andere. Het is een vorm van het primale en duale probleem dat we bij de operations research kennen en dat een belangrijk instrument voor economische analyse, en hier voor onderwijsplanning, is geworden. Volgens de nota "Economie in Maastricht" dient de aspirant-econoom in ieder geval inzicht over de volgende onderwerpen bijgebracht te worden:

- het functioneren van stelsels en bedrijven

- de methoden en technieken voor economisch onderzoek

- de samenhang tussen de economische deelwetenschappen en tussen economie en de gedrags- en maatschappijwetenschappen

- de maatschappelijke context waarin een econoom dient te functioneren.

Bezien we het programma van de eerste twee studiejaren, dan kunnen we constateren dat aan de eerste drie terreinen goed aandacht wordt besteed, zij het dat van de gedrags-en maatschappijwetenschappen alleen psychologie en sociologie aan de bak komen en dat een bescheiden inleiding in de rechtswetenschappen alleen weggelegd is voor die studenten die, halverwege het tweede jaar, voor de bedrijfseconomische basisopleiding kiezen.

Naar mijn mening zal in de toekomst een belangrijker plaats voor een inleiding Rechtswetenschappen in de basisopleiding noodzakelijk zijn, zowel uit het oogpunt van een meer evenwichtige aandacht voor alle relevante Gedrags- en Maatschappijwetenschappen als voor het verkrijgen van een beter fundament om meer juridisch getinte economische afstudeervarianten zoals Bestuurskunde en Fiscale Economie tot wasdom te kunnen brengen.

Aandacht voor de maatschappelijke, en ethische, context waarin een econoom dient te functioneren zit reeds in bescheiden mate in de basisopleiding en dient naar mijn mening in het tweede gedeelte van de studie verder gestalte te krijgen. Dat gedeelte van het studieprogramma staat momenteel nog in de steigers. 
Een derde belangrijk thema uit de nota Economie in Maastricht dat ik u wil presenteren is de inkleuring van het onderwijs aan de hand van drie aandachtsgebieden: Arbeid, Technologie en Publieke Sector.

Weliswaar is de invulling in de nota nog hoofdzakelijk algemeen economisch van karakter, maar belangrijk is dat voor het eerst in Nederland een operationeel voorstel werd gelanceerd hoe je je als faculteit kunt profileren ten opzichte van de zusterfaculteiten zonder het karakter van een all-round economische faculteit te verliezen. En de drie thema's zijn evenzovele schoten in de roos, zo bleek onlangs uit een onderzoek van de door de minister ingestelde Verkenningscommissie Economie. Zij blijken juist op terreinen te liggen waar het Nederlandse economisch onderzoek relatief zwak scoort: de welbekende gaten in de markt waar we als nieuwe faculteit nog nationale en internationale eer kunnen behalen zonder ons op de aandachtsvelden van de zusterinstellingen te begeven.

Maar, zult u wellicht denken, het ging in de nota Economie toch om de inkleuring van het onderwijs op basis van de drie aandachtsvelden en niet zozeer over de opzet van het onderzoek?

Dat klopt inderdaad, dames en heren. De laatste gedachtengang, dat profilering zo goed is voor onderzoek eerder dan voor onderwijs, is een van de modulaties die bij het uitvoeren van dit thema uit de nota Economie in Maastricht zijn aangebracht. Op de drie genoemde aandachtsvelden, Arbeid, Technologie en Publieke Sector, zullen we tenminste de helft van onze onderzoekscapaciteit alloceren en we zullen ernaar streven via dit onderzoek internationaal aansluiting te behouden of te krijgen. Dit onderzoek zal zo veel mogelijk interdisciplinair van aard zijn en zal worden aangeboden voor landelijke bescherming als Voorwaardelijk Gefinancierd Onderzoek. De andere helft van de onderzoekscapaciteit zal gebruikt worden voor vrije research, zonder welke een faculteit haar rol als grensverleggend onderzoekscentrum niet kan vervullen, en voor monodisciplinair onderzoek. Wil ons interdisciplinaire onderzoek immers het verlangde niveau behouden, en willen we op langere termijn in staat blijven nieuwe interdisciplinaire aandachtsvelden te ontwikkelen, dan dient ieder staflid naast de bereidheid tot interdisciplinaire samenwerking ook over uitstekende kennis op zijn eigen vakterrein te beschikken.

Op dezelfde wijze wordt het onderwijsprogramma geïnspireerd. Het belangrijkste uitgangspunt is dat de student zich voldoende inzicht verwerft in de vakgebieden waarin hij zich wil specialiseren en dat hij van daaruit leert met specialisten uit andere vakgebieden samen te werken. Daarom wisselen in het onderwijsprogramma perioden van specialisatie zich af met perioden van integratie, perioden waarin hij aan zijn vakmanschap 
als algemeen- of bedrijfseconoom werkt, met perioden waarin hij zijn kennis leert overdragen en van andere disciplines kennis neemt om voorgelegde problemen te ontrafelen.

En zo, dames en heren, zijn de aandachtsvelden Arbeid, Technologie en Publieke Sector de Leitmotiven geworden waar omheen we onze onderzoeksstructuur aan het opbouwen zijn en vormen diezelfde aandachtsvelden in het onderwijsprogramma de proeftuinen waarin de studenten de samenhangen tussen de verschillende vakgebieden leren kennen. En zo ook is in ons studieprogramma duidelijk plaats ingeruimd voor het toepassen van reeds verworven vakmanschap in een interdisciplinaire setting.

\section{DE OPBOUW VAN HET ONDERWIJS- EN ONDERZOEK- PROGRAMMA}

Ongemerkt, dames en heren, zijn we in de derde periode terechtgekomen van de geschiedenis van onze faculteit, de periode waarin uit alle genoemde thema's het onderwijs-en onderzoekprogramma moest worden opgebouwd. In die tijd hebben vele gesprekken plaats gevonden met Limburgse instituties zoals de 4 Kamers van Koophandel, de Werkgeversverenigingen, Provinciale en semi-overheidsinstellingen om te sonderen op welke wijze onderwijs en onderzoek het beste ingebed konden worden in het maatschappelijke leven. Dit heeft er mede toe geleid dat binnen het studieprogramma de mogelijkheid werd geschapen tot het volgen van een bedrijfseconomische en een algemeen- economische opleiding. Dit heeft er ook toe geleid dat samen met een twintigtal organisaties en ondernemingen, zowel van binnen de provinciegrenzen als daarbuiten, vele problemen zijn geformuleerd die de basis vormen van ons probleemgeoriënteerd onderwijs. Verder bleken vele economen en managers bereid voor onze studenten gastcolleges te geven en vinden er bezoeken door groepen studenten plaats bij ondernemingen en banken. De bijdrage van het bedrijfsleven aan het programma is uniek, terwijl de faculteit het toch geheel naar eigen inzicht heeft kunnen inrichten. De verwachting is gerechtvaardigd dat ook in de laatste jaren van de studie deze gerichtheid op het maatschappelijke leven doorgezet zal worden en dat daardoor en door ons probleemgeoriënteerde onderwijssysteem de studie een praktijkgerichte en praktische inslag krijgt waarbij menig economische maar ook bedrijfskundige studierichting zijn vingers af zal likken. Daarbij is ervoor gezorgd dat onze studenten qua nuttige kennis niet onder zullen doen voor hun collega's van andere faculteiten en dat zij bij hun afstuderen in staat zullen zijn op internationaal niveau de vakliteratuur te volgen. Verder waarborgt de integratie van de aandachtsvelden 
van ons onderzoek in het studieprogramma mede het wetenschappelijk karakter van de opleiding. De resultaten die tot nu toe behaald zijn, zijn hoopgevend. Het slagingspercentage voor het propaedeuse ligt nu reeds boven dat van bijna alle zusterfaculteiten, terwijl toch zorgvuldig wordt toegezien op een gelijke normering als elders. Naar verwachting zal dit slagingspercentage de komende jaren verder stijgen wanneer de onvermijdelijke kinderziektes eruit gehaald zijn.

De eerdergenoemde gesprekken met het Limburgse hebben er verder toe geleid dat hard gewerkt wordt aan de oprichting van een facultair instituut waarin zowel het fundamentele als het toepassingsgerichte onderzoek kan worden ondergebracht en dat als een duidelijk aanknopingspunt voor potentiële opdrachtgevers kan gaan functioneren. Op deze wijze wil onze faculteit trachten twee heren te dienen: de wetenschap en de regio.

Ondertussen heeft de faculteit voor het eerste interdisciplinaire onderzoeksproject op het gebied van Arbeidsmarkten en Arbeidsorganisaties landelijke erkenning en ministeriële bescherming gekregen, lopen er verschillende promotieonderzoeken en is er een begin gemaakt met contract onderzoek. Een omvangrijk ministeriëel onderzoeksproject naar aansluiting van het onderwijs op de arbeidsmarkt en de mogelijke vestiging van een afdeling van de UN University in ons voormalige klooster aan de Tongersestraat kunnen belangrijke stimulansen worden voor het onderzoeksklimaat binnen onze faculteit.

Kortom, dames en heren, de opbouw van onze faculteit is in volle gang. Natuurlijk is het niet alleen rozegeur en maneschijn. Ik wees u reeds op de problemen bij het aantrekken van gekwalificeerd wetenschappelijk personeel in de meer bedrijfsgerichte vakgebieden en onze bezorgdheid over het bestuurlijke fata morgana van Maastricht als de op éen na grootste economische faculteit van Nederland. Maar laat deze bezorgdheid bij u niet de indruk wekken dat zij ons enthousiasme over de tot nu toe behaalde resultaten overstemt.

Het tegendeel is waar. Zowel de opbouw van het onderwijs als het onderzoek verlopen voorspoedig. Ook hebben we grote waardering voor de ondersteuning door de eigen instelling en door organisaties en ondernemingen in de regio, in Limburg en elders in Nederland.

\section{DE TOEKOMST}

De komende jaren zullen we merken aan de afronding van ons studieprogramma, aan de keuze van aan te bieden afstudeermogelijkheden. We zullen onderzoeken hoe we de partners aan de vraagzijde van de 
arbeidsmarkt het beste bij de verdere inrichting van het onderwijs kunnen betrekken.

Samen met de andere faculteiten zullen we bekijken in hoeverre daar aanwezige expertise gebruikt kan worden voor de verrijking van ons afstudeerpalet.

We zullen starten met de in richting van een post doctoraal programma, zowel voor diegenen die een verdere wetenschappelijke verdieping nastreven als voor diegenen die een meer beroepsgerichte vervolgstudie willen doen. We mikken er daarbij op dat we, mede dankzij de kwaliteit van de nu reeds aanwezige onderzoekers, deel uit zullen gaan maken van een of meer landelijke centres of excellence op het gebied van economisch onderzoek en postdoctorale opleidingen.

De eerste promovendi zullen de komende jaren hun doctorsbul ontvangen. Nieuwe interdisciplinaire onderzoeksprojecten op het gebied van Technologie en de Publieke Sector zullen worden opgestart. Het onderzoeksinstituut zal zijn vleugels uit gaan slaan en, naast de transfer van wetenschappelijke kennis via doctoraal stagiaires, als katalysator op gaan treden voor het op gang brengen van onze bijdrage aan het maatschappelijke leven in deze provincie en daarbuiten.

En ik hoop dat op deze wijze onze faculteit de waardering van $u$ allen zal weten te behouden en uit te bouwen die noodzakelijk is om met vrucht te kunnen functioneren. Een waardering ook die uit moge stralen naar de gehele universiteit.

Dames en Heren, ik wil deze rede afsluiten met het aanbieden van mijn gelukwensen aan deze nu 10 jaar oude instelling en aan de gemeenschap waarvan zij deel uitmaakt.

Uw toekomst zij een voorspoedige.

\section{NOTEN}

1) Bornewasser, H.: Katholieke Hogeschool Tilburg, deel I, 1927-1954, Economie-Ethiek-Maatschappij, Ambo, Baarn 1978

2) Drift, K.D.J.M. van der, H.F.M. Crombag, A. Heertje: De contouren van een economische faculteit aan de R.U. Limburg, Bureau Onderzoek van Onderwijs Rijksuniversiteit Leiden, 1981

3) Werkgroep Economie: Economie in Maastricht, Plan voor een studierichting economie aan de Rijksuniversiteit Limburg (zonder datum). 